\title{
AVALIAÇÃO DO EQUILIBRIO DE IDOSOS INSTITUCIONALIZADOS DO MUNICÍPIO DE CANOAS - RS
}

Kelly Diana Pereira da Cruz; Ulbra; kelly.diana@rede.ulbra.br Profª Dra Lidiane Requia Alli Feldmann; Ulbra; lidiane.feldmann@ulbra.br

\section{RESUMO}

Introdução: $\mathrm{O}$ envelhecimento populacional nos últimos anos vem aumentando consideravelmente quando comparado ao passado. A senescência acarreta uma série de modificações no organismo, aumentando alguns efeitos deletérios como declínio das resevas fisiológicas, sarcopenia, dinapenia causando danos ao equilíbrio comprometendo a mobilidade e atividades básicas da vida diária. Idosos Institucionalizados são mais vulneráveis e suscetíveis a sofrerem com esses declínios, quando comparados com Idosos não Institucionalizados. Eles estão mais expostos a alguns agentes estressantes, consequentemente mais propensos a sofrerem com esses declínios aumentando o risco de quedas, trazendo consequências negativas a saúde. Objetivo: analisar os valores preditivos de equilíbrio em idosos Institucionalizados. Metodologia: Estudo transversal realizado em 2019 numa ILPI, a amostra foi composta por 19 idosos ambos os sexos, sendo 11 mulheres e 8 homens idade a partir de 60 anos residentes da instituição, o instrumento utilizado foi a Escala de Equilíbrio de Berg EEB que avalia o equilíbrio dinâmico e estático. Resultado: A média de idade das mulheres foi de 73,65 e dos homens 73,37, em relação à EEB o sexo feminino apresentou uma média de escore 13,8 enquanto sexo masculino foi de 16,2. Conclusão: $\mathrm{O}$ risco de quedas é definido quando o escore encontra-se abaixo de 45 pontos, ambos os grupos apresentaram um escore muito baixo corroborando para um risco de quedas acentuado. A literatura enfatiza a importância da capacidade funcional e o equilíbrio para a execução de atividades da vida diária dos idosos, diversos estudos evidenciam uma associação entre o estado funcional e a ocorrência de quedas.

Palavras -chave: Equilíbrio Postural; Saúde do Idoso Institucionalizado; Envelhecimento.

\section{Referências}

SANTOS, Gilmar M. et al . Valores preditivos para o risco de queda em idosos praticantes e não praticantes de atividade física por meio do uso da Escala de Equilíbrio de Berg. Rev. bras. fisioter., São Carlos , v. 15, n. 2, p. 95-101, Apr. 2011.

ARAUJO NETO, Antonio Herculano de et al . Quedas em idosos institucionalizados: riscos, consequências e antecedentes. Rev. Bras. Enferm., Brasília, v. 70, n. 4, p. 719-725, Aug. 2017. 